\title{
Apprentice selection: A systematic literature review from 1990 to 2020
}

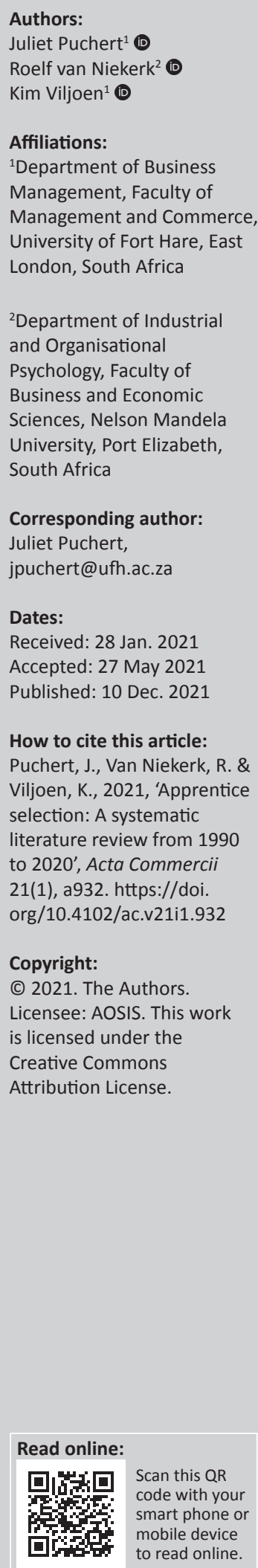

Corresponding author:

Juliet Puchert,

jpuchert@ufh.ac.za

Dates:

Received: 28 Jan. 2021

Accepted: 27 May 2021

Published: 10 Dec. 2021

How to cite this article:

Puchert, J., Van Niekerk, R. \&

Viljoen, K., 2021, 'Apprentice selection: A systematic literature review from 1990 to 2020 ', Acta Commercii 21(1), a932. https://doi. org/10.4102/ac.v21i1.932

\section{Copyright:}

(C) 2021. The Authors. Licensee: AOSIS. This work is licensed under the Creative Commons Attribution License.

Orientation: Technological innovations and developments in methods of productivity have resulted in an increased demand for technically-oriented artisans. However, the supply of qualified artisans is insufficient to meet the demand.

Research purpose: This article is the product of a systematic investigation into the extent and nature of empirical literature related to human resource selection practices used for apprentices.

Motivation for the study: The authors noted inadequate research into the selection practices used for apprentices. This investigation was motivated by the need to systematically verify the extent and nature of the empirical literature on apprentice selection, both internationally and nationally.

Research design, approach and method: A systematic literature review of published empirical research articles (for the period 1990-2020) in scholarly databases was conducted. The literature was accessed through relevant databases within the business management, human resource management and industrial psychology fields. The literature was restricted to scholarly (i.e., peer reviewed journals), English full textual data. Twelve combinations of two clusters of key words were used in the search function. The first cluster was apprentice, apprenticeship and artisan, with the second cluster being selection, selection process, staffing and recruitment. Four exclusion categories were used to reject literature that were unrelated, dissimilar and unconnected with the purpose of the literature review.

Main findings: From the comprehensive review of the literature, 12 articles were found to have content related to the selection of apprentices. Five core themes, with 11 sub-themes, were identified from this literature. A research agenda is proposed with research questions identified for each theme.

Practical/managerial implications: This literature review has provided a synthesised summary of the available literature on apprentice selection. Through the provision of a research agenda, this article contributes by providing a foundation for further research in the field.

Contribution/value-add: This article adds to the current literature available on apprentice selection practices. This should alert researchers of the need to further explore this area to enhance knowledge and understanding of the best practices employed in the selection of apprentices.

Keywords: apprentice; selection; selection process; staffing; systematic literature review.

\section{Introduction}

\section{Key focus of the study}

Economic growth, improved innovation, enhanced entrepreneurship, and business productivity are interlinked with Science, Technology, Engineering and Mathematical (STEM) skills (Xue \& Larson 2015). Industry has therefore become increasingly aware of the interplay between these STEM skills and their business success (Arvizu 2015; Kramer et al. 2015). Jobs have also become increasingly demanding given the replacement of routine tasks with advanced technology (Cedefop 2016; Giffi et al. 2015). Both internationally and within South Africa (SA), there has been an accelerated shift towards skills biased technical change (Hafni et al. 2020; Nomvete, Adams \& Moloto 2020).

Despite the heightened need for these technical skills, there is a STEM crisis. Notwithstanding enhanced employment prospects and higher earnings, there is currently an international shortage of skilled trade workers (ManpowerGroup 2018; Schwab 2019). In the United States of America (USA) alone, $67 \%$ of manufacturing employers have stated that they are not able to fill technical jobs with mid-level skilled employees (Giffi et al. 2015). In SA, a large portion of technical vacancies are not filled because of a shortage of skill and educational requirements within the populace (Mateus, Allen-Ile \& Iwu 2014; Peo 2013). A skills mismatch in the labour force is therefore explicit. It is also evident that this problem will worsen in the years to come if something 
is not done about it (Qonde 2019). To stimulate growth in global economies, it is fundamental that the continuing skills shortages in the artisanal and technical fields be addressed (Pandor 2018; Waite \& McDonald 2019).

\section{Background to the study}

The existing literature suggests that there is a quantifiable global demand for artisans (Schwab 2019). The shortage of technicians is growing more acutely daily; in certain sectors, it has been classified as a catastrophe (Heutter 2020; Kilcarr 2016). In SA, it is consistently reported that technical apprentices and artisans are scarce and critical amongst the national workforce (Government Gazette 2018; Pandor 2018). There is hence a deficiency of adequate technical abilities, specifically at the level of artisan (merSETA 2016; Nomvete et al. 2020; Vass \& Raidani 2018). Given that only approximately $24 \%-45 \%$ of learners are currently passing the trade test each year (Government Gazette 2015; Van Rooyen et al. 2010), there is a significant shortfall in the annual production rate of artisans (Duarte 2017).

This, unfortunately, is happening within a context where the country needs to strategically align its human resource (HR) practices in order to remain competitive (merSETA 2016; Nomvete et al. 2020). The competition can replicate certain assets and processes, such as operational technology and product design, but the HR asset remains unique (Breaugh 2013; Shatouri, Omar \& Igusa 2012).

It currently costs over R500 000 (South African rand) to train an apprentice in a large firm (Hauschildt 2018). It is considered vital that the right individuals are accepted onto these apprenticeship programmes (Kilcarr 2016). Firms have been encouraged to invest in enhanced screening and selection techniques for learners partaking in an artisanal learning pathway (Government Gazette 2015; merSETA 2016). The national government has also recommended, besides implementing the minimum entry requirements, that aptitude and attitude testing be carried out to assist in the selection process of apprentices (Government Gazette 2015).

However, scant national research exists on the human resource selection (HRS) practices used for apprentices (Puchert, Dodd \& Viljoen 2017a, 2017b). Specifically, there is an inadequate amount of empirical research on the profile of a successful apprentice and only modest outdated research on the profile of a successful apprentice applicant (e.g. Gump 2006; Mottram, Clarke \& Downs 1980). The optimal steps to be used in the selection and training of apprentices also need to be documented, as only limited, and mostly outdated, international empirical research is available. There is, hence, a necessity for research on the profiling and selection of apprentices (Puchert et al. 2017a, 2017b).

As Horn (2016:144) stated, 'there is only anecdotal evidence about the process of apprenticeship selection'. Discussion of apprentice recruitment and selection often refers to the staffing of graduate apprentices rather than student apprentices (e.g. Mohrenweiser 2016; Smith et al. 2011). Mohrenweiser (2016:11) mentioned the scant research by stating, 'I am not aware of any empirical paper analysing a firm's demand for apprenticeship graduates or firms' recruiting strategy in regards to apprenticeship graduates.' Imdorf and Leemann $(2012: 59,60)$ also concluded that there has been 'very little about the issue of recruitment and selection', and that with regards to apprenticeships the 'actual selection criteria applied ... have hitherto hardly been subject to any investigation'. Forsblom et $\approx a l$. (2016:403) also added that 'few studies exist that systematically examine the selection methods of training companies' involved in apprenticeship programmes.

It is the opinion of the authors of this exploratory systematic literature review (SLR) that there seems to be inadequate consideration for the role of apprentice selection in the success of apprenticeship programmes. This statement has been validated through an extensive literature review. There is not per se an absence of information on selection practices for apprentices. This SLR has confirmed that there are 12 scientific and peer-reviewed articles on the selection practices for apprentices. However, other current literature on apprentice selection is organisation specific and found mostly in the form of advertisements by training firms.

\section{Research purpose}

It is therefore vital to systematically explore what scientific knowledge is available on the topic of apprentice selection. The primary purpose of this SLR was to establish the extent and nature of empirical research on the HRS practices used for apprentices. Specifically, the authors were interested in revealing what evidence exists on the optimal process and methods to be used in the selection of apprentices. Furthermore of interest was the extent and nature of the empirical literature documenting the challenges faced in the selection of apprentices and the recommended strategies to use to overcome these challenges.

\section{Research design Research approach}

This study aims to 'comprehensively locate and synthesise research on a particular question or problem, using organised, transparent and replicable procedures at each step of the process' (Bless, Higson-Smith \& Sithole 2013:52). The approach includes an audit trail of the decisions, procedures and conclusions taken by the authors, and this facilitated a transparent and unbiased process (Atkinson \& Cipriani 2018). The approach followed in this study is a synthesis of the methods proposed by Tranfield, Denyer and Smart (2003) as well as Al-Tabbaa, Ankrah and Zahoor (2019). The approach comprised three steps, namely, (1) planning the review, (2) conducting the review, and (3) reporting and dissemination. The approach followed is depicted in Figure 1 and discussed under these three steps in the following subsections.

\section{Research method}

\section{Step 1: Planning the review}

According to Tranfield et al. (2003), the first step of planning a SLR entails determining the need for the review from a 
scoping study. Prior research performed by the authors of this SLR had confirmed a consistent need for more empirical research on artisans and apprentices, as documented in the background section of this article.

Next, a review protocol should be designed. A part of establishing this review protocol is formulating the research questions to be answered in the SLR (Webster \& Watson 2002). In relation to the confirmed broad need for more empirical research on artisans and apprentices, the authors'

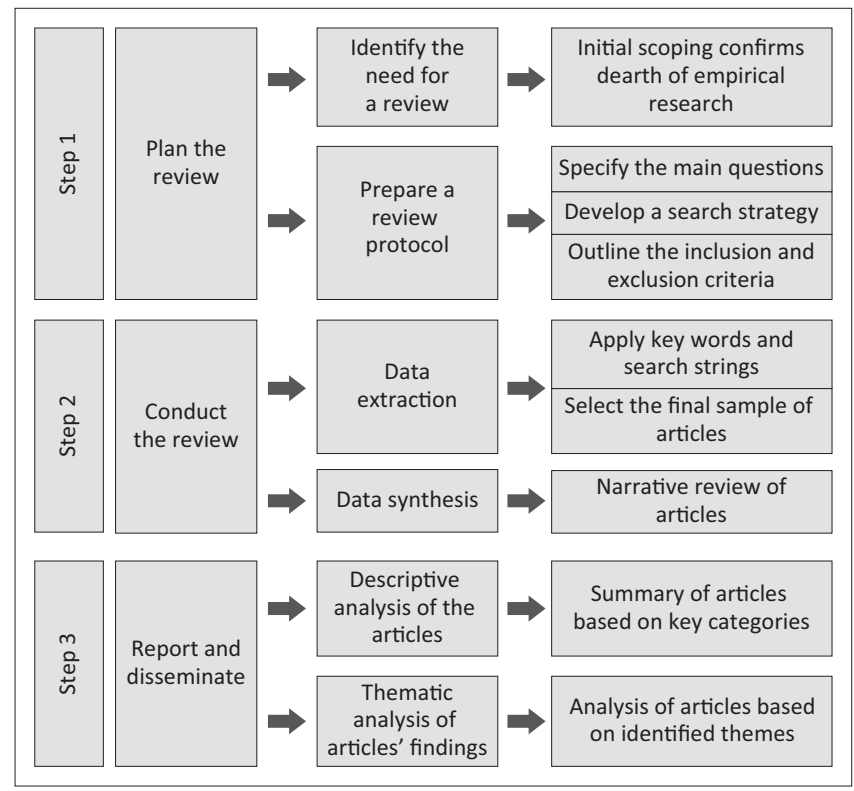

Source: Adapted from Tranfield, D., Denyer, D. \& Smart, P., 2003, 'Towards a methodology for developing evidence-informed management knowledge by means of systematic review', British Journal of Management 14, 207-222. https://doi.org/10.1111/1467-8551.00375 and Al-Tabbaa, O., Ankrah, S. \& Zahoor, N., 2019, 'Systematic literature review in management and business studies: A case study on university-industry collaboration', SAGE Research Methods Cases. https://doi.org/10.4135/9781526467263.

FIGURE 1: Steps in the systematic literature review.

TABLE 1: Search strings used in the systematic literature review.

\begin{tabular}{ll}
\hline Search string number & Key words, search string \\
\hline 1 & Apprentice + selection \\
2 & Apprentice + selection process \\
3 & Apprentice + staffing \\
4 & Apprentice + recruitment \\
5 & Apprenticeship + selection \\
6 & Apprenticeship + selection process \\
7 & Apprenticeship + staffing \\
8 & Apprenticeship + recruitment \\
9 & Artisan + selection \\
10 & Artisan + selection process \\
11 & Artisan + staffing \\
12 & Artisan + recruitment \\
\hline
\end{tabular}

primary interest was within HRS, that is, to identify the main themes in apprentice selection. This drove the delineated research purpose for the SLR as documented previously. Initially, therefore, the authors conducted an Internet scoping search using the search string 'apprentice selection'. Over 53300000 results were found. These included documents in foreign languages, those detailing the selection process used for a television programme, industry reports as well as marketing paraphernalia. The authors were not satisfied that this strategy had identified relevant literature and hence implemented a structured review protocol with inclusion and exclusion criteria.

The authors decided that the literature should be accessed through relevant databases associated with the business management, human resource management (HRM) and industrial psychology fields. These databases were EBSCOhost (Academic Search Complete, Business Source Complete, Eric, and PsycINFO®), Emerald, and ScienceDirect. These are referred to as the international databases in this article. The literature was restricted to scholarly (i.e., peer reviewed journals), English full-textual data published between 1990 and 2020. Newspapers, dissertations and periodicals were therefore excluded.

In this second stage of the planning, key words, search terms and search strings should also be determined (Tranfield et al. 2003). The authors used various combinations of two clusters of key words, used as Boolean phrases in the search function. The first cluster was apprentice, apprenticeship and artisan, with the second cluster being selection, selection process, staffing and recruitment. From these key words, 12 combinations of words, called search strings, were derived as depicted in Table 1.

According to Okoli and Schabram (2010), reviewers should indicate the practical reasons for excluding certain studies in their literature review. This allows the search strategy to be replicated by other reviewers and provides justification for the quality of the resultant literature review. In this SLR, four categories for rejecting a study were determined, which are defined and explained in Table 2.

These inclusion and exclusion criteria should be strictly employed in a SLR (Tranfield et al. 2003). In this review, the number and reasons for the inclusion and exclusion of sources were documented. The data was now ready to be extracted and synthesised according to the overall purpose of the SLR.

TABLE 2: Exclusion categories used in the systematic literature review.

\begin{tabular}{ll}
\hline Exclusion category & Description of category \\
\hline Completely unrelated studies (CUR) & $\begin{array}{l}\text { The identified purpose of the article's study was not related to the } \\
\text { primary focus of the SLR, namely, the HRS practices of apprentices }\end{array}$ \\
Unrelated studies (UR) & $\begin{array}{l}\text { These articles discussed the selection processes employed for } \\
\text { non-manufacturing-oriented apprentices. }\end{array}$ \\
Dissimilar studies (DIS) & $\begin{array}{l}\text { These studies were also on non-manufacturing-oriented } \\
\text { apprentices, but did not document content related to HRS practices. }\end{array}$ \\
Unconnected studies (UNC) & $\begin{array}{l}\text { These articles centred on manufacturing-type apprentices but } \\
\text { were not focused on their selection. }\end{array}$ \\
\hline
\end{tabular}

Examples

Articles documenting the selection of guide dogs for blind people and the selection of students into tertiary studies.

Examples included studies pertaining to the selection of doctors, nurses and clinical research officers.

For example, a study evaluating a surgical training programme for doctors was excluded.

These studies investigated other issues such as wages, assessment, health and retention.

SLR, systematic literature review; HRS, human resource selection. 


\section{Step 2: Conducting the review}

To ensure that the SLR could be easily replicated, the source and search string used were noted. The abstracts were initially reviewed to ascertain if the content was relevant to the purpose of the SLR. If it was evident that there was no linkage, the article was excluded, with the reason for the exclusion being recorded. If there was a possibility of linkage, the full-text article was sourced and reviewed in detail.

Initially, 284 articles made up the initial review sample. Across the 12 combinations of the key words, there were 51 duplications of articles and 225 were excluded for the four exclusion reasons documented in Table 2. The SLR analysis then resulted in eight articles being regarded as sufficiently associated with the purpose of this SLR and were accepted for data synthesis (see Table 3).

The planned review protocol had not yielded any research done specifically within SA. Al-Tabbaa et al. (2019) highlighted that defining the initial review sample and selecting the final sample in a SLR is by nature iterative. The authors therefore, targeted three relevant national databases for the national leg of the SLR. These were the South African Journal of Business Management, the South African Journal of Human Resource Management and the South African Journal of Industrial Psychology. These are referred to as the national databases in this article. Table 3 indicates that 40 articles were perused within these national journals, 20 of these articles were duplicates and 18 were excluded. Only four articles were accepted into this SLR.

Given the low number of articles generated through the search within these national journals, the authors decided to only input the 'selection' key word to validate the results obtained. This is in line with suggestions that an independent internet search can minimise the risk of unnecessary exclusion of articles as a result of the rigidity in the review process, which can then confirm the initial search results (Wilson et al. 2017). However, this search did not generate any novel articles for this SLR.

In total, 324 articles were initially reviewed in this SLR. Duplicate articles were excluded. The final SLR sample was extracted, which comprised of 12 articles that had a direct linkage with the research purpose of the SLR. Just over 3\% of the initial sample of reviewed articles were therefore accepted into the final review sample for data synthesis. The reference lists of these 12 articles were then further scrutinised to check if there were further articles not yet

TABLE 3: Literature search tracking sheet.

\begin{tabular}{lccccccc}
\hline Databases & \multicolumn{6}{c}{ Number of articles } \\
\cline { 2 - 7 } & Accessed & Duplicates & \multicolumn{5}{c}{ Excluded } \\
\cline { 2 - 7 } & & & CUR & UR & DIS & UNC & \\
\hline International & 284 & 51 & 169 & 33 & 6 & 17 & 8 \\
National & 40 & 20 & 11 & 4 & 0 & 3 & 4 \\
\hline Totals & $\mathbf{3 2 4}$ & $\mathbf{7 1}$ & $\mathbf{1 8 0}$ & $\mathbf{3 7}$ & $\mathbf{6}$ & $\mathbf{2 0}$ & $\mathbf{1 2}$ \\
\hline
\end{tabular}

CUR, completely unrelated; UR, unrelated; DIS, dissimilar; UNC, unconnected. revealed. However, this did not expose any articles that met all the specified inclusion criteria.

The researchers read and coded the final SLR sample of articles. Initially, the articles were catalogued based on pre-determined categories. These were: (1) names of authors, (2) publication year, (3) source, (4) number of citations, (5) search string, (6) perspective of the study, (7) context of the study, (8) sample characteristics, (9) method, and (10) key findings. Thereafter, to identify the main themes, the articles were coded using an open coding approach (Dufour \& Richard 2019). This iterative process resulted in the core themes as well as the sub-themes being identified, which denotes specific subjects investigated by the research.

\section{Step 3: Reporting and dissemination}

In step three of a SLR, a two-phase report should be compiled. A descriptive analysis of the range of research found in the review, as well as the emerging themes and questions should be provided (Tranfield et al. 2003). In line with this recommendation, the data obtained from this SLR is described in tabular tracking sheets according to key concepts or categories. Firstly, a descriptive analysis of the pre-determined categories described earlier is depicted in Table 4 and Table 5. Secondly, a synthesis of the themes derived from the final sample of articles is provided in Table 6 . On average, each reviewed article addressed three of the five core themes (a minimum of two and a maximum of five).

\section{Discussion of findings}

The review technique adopted in this SLR facilitated the establishment of patterns in the literature and allowed the authors to identify gaps that require further exploration. These are discussed in this section. Initially, general patterns in the literature are described. Following which, the main themes identified in the literature are discussed, ordered according to their degree of coverage, as depicted in Table 6.

\section{Descriptive analysis of the results}

The final sample of 12 articles is summarised in Table 4 where details are provided of publication dates, authors, database source, number of citations and search strings that resulted in the identification of the article.

\section{Publication details}

The 12 articles within this SLR were published across 7 years of publication. Given the long-standing research on the two topics, it is surprising that the first empirical study to investigate the selection of apprentices was only done in 2007. The dearth of empirical literature on this vital topic has, however, been noted by numerous other authors (Forsblom et al. 2016; Horn 2016; Imdorf \& Leemann 2012; Mohrenweiser 2016). It is the authors' hope that this article will be the stimulus for further scholarly research into this topic, and that the increased publication trend started in 2017 will continue to gain momentum. 
TABLE 4: Summary of final systematic literature review sample.

\begin{tabular}{|c|c|c|c|c|c|}
\hline Date published & Authors & Database source & Journal name & Citations & Search strings used \\
\hline \multirow[t]{2}{*}{2007} & Smith & International & Education + Training & 13 & Apprentice + recruitment \\
\hline & & & & & Apprenticeship + recruitment \\
\hline \multirow[t]{2}{*}{2008} & Hill and Dalley-Trim & International & Youth Studies Australia & 9 & Apprentice + selection \\
\hline & & & & & Apprenticeship + selection \\
\hline \multirow[t]{2}{*}{2010} & Mummenthey and Du Preez & National & South African Journal of Industrial Psychology & 18 & Artisan + selection \\
\hline & & & & & Artisan + selection process \\
\hline \multirow[t]{6}{*}{2011} & Martin and Smith & International & Adult Learning & 6 & Apprentice + selection \\
\hline & & & & & Apprentice + recruitment \\
\hline & & & & & Apprenticeship + selection \\
\hline & & & & & Apprenticeship + recruitment \\
\hline & Ziegler et al. & International & International Journal of Selection and Assessment & 51 & Apprentice + selection \\
\hline & & & & & Apprenticeship + selection \\
\hline \multirow[t]{3}{*}{2012} & Imdorf and Leemann & International & Journal of Vocational Education and Training & 34 & Apprentice + selection \\
\hline & & & & & Apprentice + recruitment \\
\hline & & & & & Apprenticeship + selection \\
\hline \multirow[t]{3}{*}{2016} & Forsblom et al. & International & Journal of Vocational Education and Training & 6 & Apprenticeship + recruitment \\
\hline & Horn & International & Social Science Research & 15 & Apprentice + selection \\
\hline & & & & & Apprenticeship + selection \\
\hline \multirow[t]{15}{*}{2017} & Imdorf & International & Journal of Vocational Education and Training & 19 & Apprentice + selection \\
\hline & & & & & Apprentice + recruitment \\
\hline & & & & & Apprenticeship + selection \\
\hline & & & & & Apprenticeship + recruitment \\
\hline & Naidoo and Hoque & National & South African Journal of Human Resource Management & 4 & Apprentice + selection \\
\hline & & & & & Apprentice + selection process \\
\hline & & & & & Apprenticeship + selection \\
\hline & & & & & Artisan + selection \\
\hline & & & & & Artisan + selection process \\
\hline & & & & & Artisan + recruitment \\
\hline & Puchert et al. (b) & National & South African Journal of Industrial Psychology & 1 & Apprenticeship + selection \\
\hline & & & & & Apprenticeship + recruitment \\
\hline & & & & & Artisan + selection \\
\hline & & & & & Artisan + selection process \\
\hline & & & & & Artisan + recruitment \\
\hline
\end{tabular}

Across the 12 articles, there are 23 authors. There were two common sets of authors. From the articles accessed through the international databases, Imdorf co-authored with Leemann on the 2012 article and was also the sole author of one of the 2017 articles. Puchert, Dodd and Viljoen wrote two of the 2017 articles sourced through the national databases.

The 12 articles from this SLR have harvested 178 citations. Just under half ( $n=85,48 \%$ ) of these citations are from two articles: (1) Ziegler et al. (2011) at 51 citations, and (2) Imdorf and Leemann (2012) at 34. Interestingly, both of these articles evaluated selection processes employed for a range of apprenticeship types. There is a clear interest in the selection methods and processes that can predict the training success of apprentices. Future research should replicate the research performed by these two sets of authors to further investigate and substantiate the predictability of their findings.

A significant number $(n=5)$ of the 12 articles were written for journals focussing on industrial psychology and HRM topics. Four of the articles were published in vocational education and training journals, two in general education and training journals, and one in a social science journal. This highlights that the apprentice selection topic is of widespread interest.

The vast majority $(n=8)$ of the articles were sourced from international databases. Three of the four articles obtained from national databases, however, were the most recent empirical research carried out within the topic. From these national databases, seven search strings generated articles. The two search strings with the highest acceptance rate (i.e., all four articles each) were the artisan + selection and artisan + selection process categories. Only 5 of the 12 search strings analysed in the international databases generated articles that were accepted for further review. Here, the two search strings with the highest acceptance rate (i.e., seven of the eight articles each) were the apprentice + selection and apprenticeship + selection categories. None of the artisanrelated search strings generated relevant articles for this SLR. Whilst the apprentice and apprenticeship related search strings were more successful in generating relevant articles, the national databases leant more towards search strings referring to the term artisan. 


\section{Context}

In terms of research setting, five of the articles were conducted in Europe, four in SA, two in Australia and one in the USA. None of the articles allude to the location specificity of their findings. However, the findings from the European articles refer to the dual apprenticeship system, whilst the Australian, USA and South African research were conducted in out-ofschool apprenticeship systems. As highlighted in a previous SLR related to the artisan field by Pret and Cogan (2019), future research in this field should explore if their findings are context-specific or whether they are generalisable to other contexts.

It is also noteworthy that none of the research found in this SLR stems from outside of western culture. This despite the apprenticeship system having a long history in both China (Risler \& Zhiqun 2013) and India (Fazio, Fernández-Coto \& Ripani 2016). Only the Imdorf and Leemann (2012) article referred to the role of culture in their findings. Future studies could explore the impact culture plays in the selection of apprentices. This could be from an organisational culture perspective and/or the culture of the applicants and recruiters.

\section{Research approaches and method}

There was a spread of research approaches adopted across the 12 articles within the SLR. As reflected in Table 5, three were pure qualitative studies, four were mixed, and five were quantitative. Interestingly, there are no national articles that had a qualitative approach. All the qualitative studies made use of the interview research method. The interview research method was also used in all four articles that employed a mixed research approach.

Of the seven articles that had interviews within the research methodology, only two contained information from interviews with the actual apprentices. These were the articles written by Hill and Dalley-Trim (2008) and Mummenthey and Du Preez (2010). Managers involved in the recruitment of apprentices were interviewed (i.e., Forsblom et al. 2016; Imdorf 2017; Imdorf \& Leemann 2012; Martin \& Smith 2011; Smith 2007) as were the trainers of the apprentices (i.e., Forsblom et al. 2016; Imdorf \& Leemann 2012). The two aforementioned articles also contained information from the perspectives of managers, trainer providers and even training authorities. Their multifaceted approach to understanding apprentice selection from the various role-players perspectives is powerful, especially their inclusion of the apprentices themselves. Given that only two of the seven articles that used interviewing thought to consider the perspective of the actual apprentice in their studies is informative. Improving applicants' experience of any screening process is a core goal of most employers. It is therefore not surprising that more research is conducted on the experiential perceptions of applicants than any other aspect of selection (Schmitt 2014). This is because of the potential negative impact on the organisation's brand and reputation should applicants have a negative experience during the selection process (Anderson, Salgado \& Húelsheger 2010; Trindale 2015). Future research should

TABLE 5: Descriptive analysis of final systematic literature review sample.

\begin{tabular}{|c|c|c|c|c|c|c|}
\hline Date & Authors & Perspective & Country & Sample & Method & Key findings \\
\hline 2007 & Smith & $\begin{array}{l}\text { Recruitment and } \\
\text { development strategy }\end{array}$ & Australia & Six senior managers & Qualitative & $\begin{array}{l}\text { Differential outcomes achieved in recruiting } \\
\text { and developing apprentices based on the } \\
\text { company's skill and experience. }\end{array}$ \\
\hline 2008 & Hill and Dalley-Trim & Retention factors & Australia & $\begin{array}{l}\text { Profile of } 193 \\
\text { apprentices, } 13 \\
\text { interviews }\end{array}$ & Mixed & $\begin{array}{l}\text { The completion of the first year of } \\
\text { apprenticeship was aided by school subject } \\
\text { choice, work-related experience and a } \\
\text { supportive home life. }\end{array}$ \\
\hline 2010 & $\begin{array}{l}\text { Mummenthey and } \\
\text { Du Preez }\end{array}$ & Evaluation of learnerships & South Africa & $\begin{array}{l}4 \text { stakeholder } \\
\text { groupings }\end{array}$ & Mixed & $\begin{array}{l}\text { Despite low satisfaction, the learnership system } \\
\text { is an appropriate way to develop artisans }\end{array}$ \\
\hline \multirow[t]{2}{*}{2011} & Martin and Smith & $\begin{array}{l}\text { Critical analysis of adult } \\
\text { education }\end{array}$ & $\begin{array}{l}\text { United States of } \\
\text { America }\end{array}$ & 3 training programmes & Mixed & $\begin{array}{l}\text { Multiple hurdle selection approach was } \\
\text { recommended. }\end{array}$ \\
\hline & Ziegler et al. & $\begin{array}{l}\text { Predictability of selection } \\
\text { tools }\end{array}$ & Germany & 771 apprentices & Quantitative & $\begin{array}{l}\text { General mental ability, some specific } \\
\text { cognitive ability tests and structured } \\
\text { interviews were strong predictors of } \\
\text { training performance. }\end{array}$ \\
\hline 2012 & Imdorf and Leemann & $\begin{array}{l}\text { Fairness and selection } \\
\text { methods }\end{array}$ & Switzerland & 9 interviews & Qualitative & $\begin{array}{l}\text { Case study showed a fairer selection process } \\
\text { (i.e., determined more by performance and } \\
\text { less by applicants' social attributes). }\end{array}$ \\
\hline \multirow[t]{2}{*}{2016} & Forsblom et al. & Selection and dropouts & Switzerland & $\begin{array}{l}335 \text { trainers and } \\
\text { managers }\end{array}$ & Mixed & $\begin{array}{l}\text { Apprenticeship dropouts were significantly } \\
\text { less if job interviews and a company visit were } \\
\text { used. }\end{array}$ \\
\hline & Horn & Employment trends & Hungary & 37027 students & Quantitative & $\begin{array}{l}\text { No significant differences between apprentices } \\
\text { and non-apprentices' employment } \\
\text { opportunities. }\end{array}$ \\
\hline \multirow[t]{4}{*}{2017} & Imdorf & Discrimination and hiring & $\begin{array}{l}\text { Switzerland and } \\
\text { Germany }\end{array}$ & 81 owners or managers & Qualitative & $\begin{array}{l}\text { Ethnicity and other discriminatory categories } \\
\text { are used as trouble avoiding resources when } \\
\text { hiring. }\end{array}$ \\
\hline & Naidoo and Hoque & $\begin{array}{l}\text { Success factors to } \\
\text { employment }\end{array}$ & South Africa & 51 artisans & Quantitative & $\begin{array}{l}\text { Quality of workplace environment had a } \\
\text { significant impact on permanent employment }\end{array}$ \\
\hline & Puchert et al. (a) & Selection methods & South Africa & 2463 applicants & Quantitative & $\begin{array}{l}\text { Multiple-hurdle selection approach } \\
\text { recommended, with secondary education type } \\
\text { being a cost-effective preliminary screening } \\
\text { method. }\end{array}$ \\
\hline & Puchert et al. (b) & Selection methods & South Africa & 1566 applicants & Quantitative & $\begin{array}{l}\text { Recommended using type of secondary } \\
\text { education as a selection tool for high volume } \\
\text { low-level technical positions. }\end{array}$ \\
\hline
\end{tabular}


therefore highlight the applicants' perspective of the apprenticeship selection process.

The largest sample size used in the articles that employed a qualitative research approach was 81 (i.e. Imdorf 2017) and 135 (i.e. Mummenthey \& Du Preez 2010) in the mixed method type articles. The next highest sample size of individuals interviewed was 18 (i.e. Forsblom et al. 2016), with the average sample size across the other four articles being eight individuals.

Recently, there has been considerable interest in the methods used by qualitative researchers to justify their sample size (Sim et al. 2018; Vasileiou et al. 2018). Data saturation is a commonly used method (Braun \& Clarke 2019). However, authors have cautioned qualitative researchers to pay careful attention to the way they justify small sample sizes. Researchers should ensure their qualitative research is contributing robust and rigorous findings (Boddy 2016; Kindsiko \& Poltimäe 2019), as the insufficiency of sample size could threaten the validity and generalisability of such studies (Vasileiou et al. 2018).

The method used to determine the sample size in the seven articles from this SLR that used interviews is not mentioned. From what is not written in this regard in these seven articles, it could be concluded that the small sample sizes were pre-determined based on convenience rather than on the achievement of saturation point in the analysis. The small sample sizes of these studies could be a research methodology flaw.

Another critique levelled at some of the articles within this SLR is the currency of their data. Three of the articles (i.e., Hill \& Dalley-Trim 2008; Imdorf 2017; Smith 2007) are based on data from the 3-year period 2004-2006. The publication dates of two of the articles reveal that they were written shortly after data collection, whilst Imdorf (2017) concedes that he did a secondary analysis of the data. Are the results from these studies still relevant today? Given the noted widespread deficiency in qualified artisans (Pandor 2018; Qonde 2019), current research is vital. Recent relevant research is needed to provide ways to minimise the challenges inherent in addressing this shortage and highlight the tools to improve the throughput rates of enrolled apprentices.

The authors of two of the SLR articles (i.e., Forsblom et al. 2016; Imdorf \& Leemann 2012) highlighted other research method limitations in their findings. The former set of authors encouraged quantitative longitudinal studies to confirm the predictive effects of their preliminary findings, with the latter set of authors indicating that statistically validated evidence is necessary to endorse their hypotheses.

Following a descriptive analysis of the 12 articles in this SLR, the next part offers a thematic analysis of the five main themes derived from these articles.

\section{Thematic analysis of the results}

\section{Key selection criteria theme}

Within the key selection criterion theme, two sub-themes were identified. As illustrated in Table 6, these were the personal characteristics of applicants and the academic marks obtained by these applicants.

The majority of the articles referred to the personal characteristics of the applicants as being a key determinant in the selection of an apprentice. What was specifically included within the definition of important personal characteristics did differ across the eight articles, but there were obvious similarities also.

Being internally motivated and committed was a strong theme. Martin and Smith (2011) documented a 'commitment hurdle' step where applicants were required to go to an unknown location. Those who completed this step had adequate self-confidence and motivation to make it through the apprenticeship process. Horn (2016) found that students who organised their own apprenticeship training (i.e. not organised through the school for them) were more motivated and more likely to be employed post-graduation than the school-organised apprentices. Imdorf and Leemann (2012) found that a short internship placement helped ascertain the applicants' motivational levels and that this aided with organisational fit. Ziegler et al. (2011) also concurred that the motivational and interest levels of applicants, determined through a structured interview, was a strong predictor of apprenticeship training success. A positive attitude, enthusiasm and passion for the work itself will lead to lower drop-out rates in apprenticeship programmes (Hill \& DalleyTrim 2008; Mummenthey \& Du Preez 2010).

Smith (2007) coined the term 'stickability' as descriptive of the cluster of personal characteristics needed within an applicant who will be successful in an apprenticeship programme. These soft skills included punctuality, appearance, willingness to learn and reliability. Hill and Dalley-Trim (2008) added initiative, respect, resilience, teamwork skills and being mature in behaviour towards others and the job itself, to the list of personal characteristics that are likely to lead to applicants completing an apprenticeship programme. What Smith (2007) described as 'stickability' is termed 'a person with quality' by Imdorf and

TABLE 6: Themes in apprentice selection research.

\begin{tabular}{ll}
\hline Main theme & Sub-themes (ordered by frequency of occurrence) \\
\hline Key selection criteria & $\begin{array}{l}\text { Personal characteristics (8) } \\
\text { Academic marks (8) }\end{array}$ \\
Research intention & $\begin{array}{l}\text { Improve quality (8) } \\
\text { Fairness (2) } \\
\text { Retention (2) }\end{array}$ \\
Support strategies & $\begin{array}{l}\text { Preparation workshops (8) } \\
\text { Career guidance (3) }\end{array}$ \\
Selection methods & $\begin{array}{l}\text { Aptitude testing (5) } \\
\text { Interview (5) }\end{array}$ \\
Diversity & Gender (3) \\
& Race (2) \\
\hline
\end{tabular}


Leemann (2012). Along with all the personal attributes already mentioned, these authors also found that being adjustable, flexible and able to cope with a variety of situations as vital personal characteristics.

In contrast, Naidoo and Hoque (2017) established that a high work ethic did not have a significant impact on the attainment of permanent employment post-apprenticeship. This may be attributable to this study being the only quantitative study with a moderate size sample to have sought the opinion of apprentices. The other four articles that commented on this aspect were based on qualitative interviews with owners and/or trainers whose opinions on the importance of these personal characteristics may therefore be divergent. This should be further investigated.

Another sub-theme in terms of selection criteria was the use of academic subject choice and the marks obtained. Hill and Dalley-Trim (2008) made a strong case for subject choice at school. The types of subjects chosen were informative of the difference between continuing and non-continuing apprentices, with the majority having no vocationally-related school subjects discontinuing. Applicants for low-level technical positions with secondary education types inclusive of mathematics and/or science had enhanced success in the screening process and better chances of employability (Puchert et al. 2017a, 2017b).

The other articles that contributed to this sub-theme documented the use of academic marks as an initial screening mechanism. In the Smith (2007) article, attained school marks were one of four criteria used in choosing applicants for an apprenticeship. On average, employers ranked the use of school marks as being of moderate importance, with one of the six case studies stating it was a criterion of high importance. Both Smith (2007) and Horn (2016), however, confirmed that employers do not view school marks as the most important criteria, but merely one, of the criteria to be applied in the screening of apprenticeship applicants. Five other articles (i.e. Imdorf \& Leemann 2012; Martin \& Smith 2011; Puchert et al. 2017a, 2017b; Ziegler et al. 2011) discussed school mark attainment as a necessary initial screening step. This first step of a multiple hurdle selection process enabled a cost-effective means to achieve a significant drop in the number of applicants to consider. These findings could be further explored for clarification. Future research could verify which subjects, academic or vocational, are considered key selection subjects, and what would be regarded as the minimum marks for further consideration.

The second core theme pertained to research intention. As indicated in Table 6, three sub-themes emerged, namely, the improvement of the quality of apprentices, the fairness of the hiring practices employed, and the retention of apprentices during their development. These are discussed in the following sections.

\section{Research intention theme}

The intention behind the research of 8 of the 12 articles in this SLR was to investigate ways to improve the quality of the applicants for an apprenticeship. The majority $(n=6)$ of these articles were primarily focused on the selection process or methods used to create this outcome. Smith (2007), Martin and Smith (2011), Ziegler et al. (2011), Forsblom et al. (2016) as well as Puchert et al. (2017a, 2017b) explored this angle as a critical success factor or strategy that could be used to enhance the quality of apprenticeship applicants. On the other hand, for Mummenthey and Du Preez (2010) and Naidoo and Hoque (2017), the hiring process itself was only one of the many angles that were pursued to facilitate this outcome. Their research looked more holistically at the entire apprenticeship life cycle.

The articles written by Imdorf and Leemann (2012) and Imdorf (2017) also specifically looked at the hiring practices employed in apprenticeship programmes, but from the angle of investigating the fairness of these selection methods. Both pursued whether ethnic discrimination was being applied through the selection methods used by training companies.

The third and final sub-theme regarding research intention involves two articles whose focus was the retention of apprentices during their training and development. The selection methods used were discussed and the data from the selection process were part of the analysis, but not from the perspective of reducing the number of drop-outs during the programme. Hill and Dalley-Trim (2008) looked specifically at the factors in the first year of training that differentiated drop-outs from those who continued, whilst Horn (2016) took a more long-term approach and investigated the key factors that impacted on employability post the apprenticeship programme.

From this theme, then, one can conclude that the selection of apprentices, as a key HR practice, was only primarily investigated by half the articles in this SLR. Providing empirical research that added to the knowledge base of HRS was merely a by-product of the studies conducted by the authors of the other six articles. Four critiqued the apprenticeship programme from a training and developmental perspective (i.e. Hill \& Dalley-Trim 2008; Horn 2016; Mummenthey \& Du Preez 2010; Naidoo \& Hoque 2017), and two (i.e., Imdorf \& Leemann 2012; Imdorf 2017) looked at discrimination in hiring from the sociological viewpoint. Further research, specifically, on the impact of and optimal methods to use in the selection of apprentices is therefore needed.

The next core theme was the strategies employed to overcome the challenges experienced in the selection of apprentices. In order of frequency, these are preparation workshops and career guidance provided to the apprenticeship applicants.

\section{Support strategies theme}

The first theme noted that if applicants held certain personal characteristics, these were helpful in their selection onto the 
programme, being successful on the programme itself as well as improving their employment opportunities post the programme. Employers used various strategies to better prepare the applicants for success and to assist them in developing these required turnkey attributes.

Some provided tutoring for applicants who did not make their cut-off standards in mathematics, literacy and other social skills as identified within one of the selection hurdles (Martin \& Smith 2011). Subject choice and achievement in the subjects of mathematics and/or science were crucial for selection, making additional educational support in these subjects critical (Puchert et al. 2017a, 2017b). The mentorship provided within an apprenticeship programme had a significant impact on the permanent employment prospects of those apprentices. This mentorship was regarded as a critical success factor in the development of the appropriate work ethic skills (Naidoo \& Hoque 2017). Smith (2007) recommended that applicants complete a pre-apprenticeship, as this would assist in ensuring that applicants had the required skills and a good understanding of the specific industry.

This strategy of preparing applicants for an apprenticeship is in line with literature outside of the artisan educational track. There is, in fact, a need to improve the way youth prepares for the world of work (Fox 2018; DuRose \& Stebleton 2016). Potential employers need to consider various strategies, such as conducting orientation sessions and job application preparedness workshops, to enhance employability and better facilitate the transition of students into the workplace (merSETA 2016; Shankar, Cooper \& Koh 2016). Future research should investigate the impact of such preparation workshops on apprentice selection.

The second sub-theme was the timely provision of career advice to apprenticeship applicants. Smith (2007) as well as Hill and Dalley-Trim (2008) found that the successful completion of apprenticeship programmes was linked to the applicants having clear knowledge and understanding of what their trade involved and the career path ahead of them. Naidoo and Hoque (2017) also established that training and development opportunities with a clear talent pipeline into management had a significant impact on apprentice retention. Apprentices make their decision to either continue or not based on an apprenticeship programme fairly quickly. Hill and Dalley-Trim (2008) documented that this decision was made within the first 90 days of the programme. Their research established that government initiatives to improve the career guidance offered to apprentice applicants helped lower the drop-out rate. More research is needed to corroborate the nature of the relationship between career guidance provision and the selection of apprentices.

As indicated in Table 6, the next identified theme looked at the frequency of selection methods employed in the hiring of apprentices. Two sub-themes that emerged from this theme are: aptitude testing and interviewing.

\section{Selection methods theme}

Five of the articles describing selection methods employed for the hiring of apprentices discussed the use of aptitude testing. All five articles described this method as a preliminary screening tool, used after the review of the application documentation, but before interviewing the applicant. Aptitude testing was used as a method to reduce the large pool of applicants to a more manageable size. General cognitive ability testing was used in the selection processes documented by Martin and Smith (2011), Ziegler et al. (2011), Imdorf and Leemann (2012), and Puchert et al. (2017a). The testing of special aptitudes was reported on in the selection processes outlined by Puchert et al. (2017b) and Ziegler et al. (2011).

Five articles mentioned the use of interviews as a screening mechanism for apprenticeship applicants. Martin and Smith (2011) provided a critical analysis of three pre-apprenticeship workforce training programmes. In two of these case studies, the interview selection method was the final hurdle to successful selection onto the programme. In the Ziegler et al. (2011) article, the structured interview was deemed a strong predictor of training performance and was also recommended as a final selection method for apprentices. These authors suggested that the unstructured interview format should not be used, and Forsblom et al. (2016) agreed with this. Structured, formal job interviews were highly recommended as a means to reduce the number of drop-outs in a programme. Informal interviews would not achieve the same level of connection with the apprentice applicant. Imdorf and Leemann (2012) also outlined a four-stage selection process with an interview as the second last stage. In this case study, however, a short placement within the firm was the final and determining selection method.

Smith (2007) did not specifically mention any selection method in his article. However, in their ranking of selection criteria, the senior management sample rated soft skills and management suitability (i.e., punctuality, appearance, reliability factors) as the top two criteria. Whilst not explicitly stated it would be appropriate to assume that these recruiters would have gleaned this information from interviews with the applicants. Recruiters are mostly interested in the attitudes, interests, fit, personality and portable social skills of applicants (Branine 2008; Fernández-Aráoz 2014). Interviews can determine the consistency of these characteristics against those required for the position (Azar et al. 2013; Straus, Miles \& Levesque 2001). Interviews, therefore, are mostly used to establish if the applicant has the personal attributes and soft skills deemed as vital selection criteria, as discussed in the first theme of this SLR.

Whilst these six articles documented the various steps in the selection processes used in their case studies, none provided insight into the impact or value of each step on the final outcome of the selection process. As Forsblom et al. (2016) highlighted, no causal statements can be made from this research. A longitudinal study is, therefore, necessary to confirm the predictive effects of these various selection methods. 
In the next subsection the final theme is discussed. As indicated in Table 6, there are two sub-themes within this theme.

\section{Diversity theme}

Discrimination was a key theme through some of the studies. Martin and Smith (2011) found a gender discrepancy in the selection practices employed in Britain. These authors specifically documented the low number of females recruited within the three case studies they investigated. They concluded that little effort had been made to recruit females into these programmes and only one out of five who was recruited had actually graduated.

In the research done by Hill and Dalley-Trim (2008), 24\% of the apprentices were female. In the Forsblom et al. (2016) study the female portion was only $12 \%$. Whilst these two articles did not specifically mention gender discrimination, it is implicit in their sample sizes.

This supports the notion that apprenticeships remain maledominated (merSETA 2016; Qonde 2018). Furthermore, lower pay and less favourable career progression routes have been noted within traditionally female-dominated apprenticeships, such as healthcare, business administration and child care (Gambin \& Hogarth 2015). Additional research into the selection-related strategies that can be applied to circumvent this gender discrimination challenge within the apprenticeship system is paramount.

Imdorf (2017) found that Swiss and German firms use nationality and ethnicity as a screening mechanism. Imdorf and Leemann (2012) suggested that outsourcing the selection process of apprentices, as employed by occupational training networks, was a more efficient and less discriminatory alternative. However, the authors of this explorative case study also noted that more evidence was needed to confirm that this was an equal opportunity model before it was replicated. As suggested by Imdorf (2017), more research is needed to understand the emerging patterns of ethnic discrimination in apprenticeship selection practices.

\section{Conclusion and proposed research agenda}

The most difficult positions to currently fill, internationally and within SA, are skilled trade positions (Deloitte 2018; Heutter 2020; Kilcarr 2016; Qonde 2019). They have dominated this top position since 2010 (ManpowerGroup 2018). Abounding literature indicates that firms with welldeveloped selection practices will have significantly lower employee turnover, higher productivity and overall financial performance (Hoffman, Kahn \& Li 2018; Schmidt, Oh \& Shaffer 2016). Furthermore, weaknesses in HRS processes could have dire and widespread consequences for a firm (Aladwan, Bhanugopan \& D'Netto 2015; Ekwoaba, Ikeije \& Ufoma 2015; Trindale 2015). Given these empirical findings, one is led to ask: why are there only a paltry 12 scientificallybased articles on the selection of apprentices?

This SLR has confirmed that there is a research gap that needs to be addressed, both internationally and nationally. It is hoped that this article will encourage researchers and practitioners to share their practical information on apprentice selection in a scientific manner and thereby stimulate further knowledge and improvement in this field. This is especially needed given the high demand for artisans, the lack of a national selection tool and the variable pass rates of apprenticeship programmes.

This SLR is based on a small number of studies. Rather than a weakness, the authors believe this is a strength. Other SLR authors have encouraged small sample sizes as this facilitates critical engagement with each article and its underpinning themes (Baldacchino et al. 2015; Korsgaard 2013). Through using strict search criteria the authors of this SLR ensured that the included 12 articles were relevant and focussed as well as of a high quality.

Several conclusions can be drawn from a review of the extant literature within this SLR. Furthermore, substantial clues for future research can be gleaned from a review of these 12 articles. These are summarised as research questions in a research agenda within Table 7.

A review of the general trends in the literature reveals that the quantity and quality of empirical work into apprentice selection requires improvement. The most recent articles were published in 2017, meaning that the actual data must at least be 6 years old. There is also a need for studies on apprentice selection from the business management discipline. Research in this regard should accurately predict emerging challenges in apprentice selection and offer potential solutions to this workforce problem. Research should also focus on the recent trends in apprentice selection, especially within the post coronavirus disease 2019 (COVID-19) pandemic era.

Additional qualitative research will provide vital information, especially from to date almost silent voice of the actual apprentice. The sample size of these future qualitative studies also needs to be carefully considered. Robust, replicable quantitative research, such as done by Ziegler et al. (2011) and Naidoo and Hoque (2017), is also needed. These studies should attempt to replicate the predictability of the same or other selection methods and processes. Studies need to be done to either verify or refute the findings established by these 12 articles. Longitudinal studies such as that done by Horn (2016) will provide substantial practical advice for the many stakeholders who have a vested interest in enhancing the number of skilled and qualified technical workers in the labour market.

In terms of providing advice and/or recommendations for the successful selection of apprentices, only six studies offered concrete findings in this regard. Most of the studies from this SLR recommended the use of a multiple-hurdle 
TABLE 7: A research agenda for apprentice selection.

\begin{tabular}{|c|c|}
\hline Theme & Key research questions \\
\hline \multirow[t]{7}{*}{ General trends } & What are the apprentice selection research trends post-2017? \\
\hline & Which selection methods and processes can predict the training success of apprentices? \\
\hline & Are research findings in apprentice selection context-specific or, are they generalisable to other contexts? \\
\hline & What role does culture play in the selection of apprentices? \\
\hline & How could qualitative research from the applicants' perspective inform apprentice selection? \\
\hline & Would larger samples in qualitative research provide similar results to those found in this SLR? \\
\hline & How would information from longitudinal studies on apprentice selection inform the field? \\
\hline \multirow[t]{5}{*}{ Key selection criteria } & Are the personal characteristics or work ethic of applicants a key selection criterion? \\
\hline & If so, how are these characteristics defined? \\
\hline & Are the subjects completed by applicants a key consideration in their selection as apprentices? \\
\hline & If so, what subjects are preferred? And why? \\
\hline & What are the optimum minimum marks for previous education or training initiatives done by applicants? \\
\hline Research intention & What is the best process to use in the selection of apprentices? \\
\hline \multirow[t]{2}{*}{ Support strategies } & How do preparation workshops impact on the selection of apprentice selection? \\
\hline & What is the relationship between career guidance provision and the selection of apprentices? \\
\hline Selection methods & What are the predictive effects of various selection methods on the successful completion of an apprenticeship programme? \\
\hline \multirow[t]{4}{*}{ Diversity } & What are the emerging patterns regarding gender discrimination within apprenticeship selection practices? \\
\hline & What selection related strategies can be applied to circumvent the gender discrimination challenge within the apprenticeship system? \\
\hline & What are the emerging patterns of ethnic discrimination within apprenticeship selection practices? \\
\hline & What selection related strategies can be applied to circumvent the ethnic discrimination challenge within the apprenticeship system? \\
\hline
\end{tabular}

SLR, systematic literature review.

selection process. However, whilst some recommended the use of certain methods (i.e., structured job interviews and cognitive ability tests), others suggested substituting more expensive psychological testing with secondary education as a screening measure. Future research needs to confirm the optimum selection criteria and selection methods to employ in the selection of apprentices.

And a final suggestion regarding future research. To validate the findings from this SLR, it is suggested that researchers conduct a similar SLR to establish if other studies are discovered. All evidence can have invisible biases created by untried assumptions and frames of reference. The researcher has a particular purpose in mind and this can skew their interpretation (Rousseau, Manning \& Denyer 2008). A future SLR on this topic could investigate the topic within specific sectors or from different angles and with different key words or search strings.

\section{Limitations}

Authors on systematic research recommend that the review should not be limited to bibliographic databases and published journals. Unpublished studies, the Internet, conference proceedings and industry reports should also be considered in the review process (Tranfield et al. 2003). However, this SLR explicitly aimed to establish the extent and nature of peer-reviewed research that had previously been done on the subject matter. Nevertheless, non-empirical yet credible research might possibly have been overlooked through implementing this exclusion criterion. The specific keywords and search strings used to guide this SLR could also have contributed to omitting certain published work. Furthermore, the specific databases and journals selected for this SLR can also be regarded as a limitation.
According to Tranfield et al. (2003) as well as Okoli and Schabram (2010), an assessment of the quality of the studies reviewed should be completed before the final inclusion of articles into a SLR. However, no quality assessment of the articles was done in this SLR. All the articles that met the stipulated criteria were accepted if their purpose and sample were aligned to the study's objectives.

\section{Acknowledgements Competing interests}

The authors declare that they have no financial or personal relationships that may have inappropriately influenced them in writing this article.

\section{Authors' contributions}

J.P., R.v.N. and K.V. all contributed equally to the writing of this article.

\section{Ethical considerations}

This article followed all ethical standards for research without direct contact with human or animal subjects.

\section{Funding information}

This research received no specific grant from any funding agency in the public, commercial, or not-for-profit sectors.

\section{Data availability}

The data that support the findings of this study are available from the corresponding author, J.P., upon reasonable request. 


\section{Disclaimer}

The views expressed in this article are the those of the authors' and not an official position of their institutions.

\section{References}

Aladwan, K., Bhanugopan, R. \& D'Netto, B., 2015, 'The effects of human resource management practices on employees' organisational commitment', International Journal of Organizational Analysis 23(3), 472-492. https://doi.org/10.1108/IJOA11-2014-0822

Adams, W., Mjikeliso, N., Pretoriuos, S., Van der Linde, E., Nomvete, S. M., Letsoalo, L. 2021. Strategic plan for the fiscal years 2015/16-2019/2020. viewed 01 December 2021, from https://www.merseta.org.za/wp-content/uploads/2021/04/merSETAStrategic-Plan-2019_2020.pdf

Al-Tabbaa, O., Ankrah, S. \& Zahoor, N., 2019, 'Systematic literature review in management and business studies: A case study on university-industry collaboration', SAGE Research Methods Cases. https://doi.org/10.4135/9781526467263

Anderson, N., Salgado, J.F. \& Húelsheger, U.R., 2010, 'Applicant reactions in selection: Comprehensive meta-analysis into reaction generalization versus situational specificity', International Journal of Selection and Assessment 18, 291-304. https://doi.org/10.1111/j.1468-2389.2010.00512.x

Arvizu, D.E., 2015, Revisiting the STEM workforce: A companion to science and engineering indicators 2014, National Science Foundation, viewed 14 September 2020, from https://nsf.gov/pubs/2015/nsb201510/nsb201510.pdf.

Atkinson, L. \& Cipriani, A., 2018, 'How to carry out a literature search for a systematic review: A practical guide', BJPsych Advances 24, 74-82. https://doi.org/10.1192/ bja.2017.3

Azar, A., Sebt, M.V., Ahmadi, P. \& Rajaeian, A., 2013, 'A model for personnel selection with a data mining approach: A case study in a commercial bank', South African Journal of Human Resource Management 11(1), 1-10. https://doi.org/10.4102/ sajhrm.v11i1.449

Baldacchino, L., Ucbasaran, D., Cabantous, L. \& Lockett, A., 2015, 'Entrepreneurship research on intuition: A critical analysis and research agenda', International Journal of Management Reviews 17(2), 212-231. https://doi.org/10.1111/ ijmr.12056

Bless, C., Higson-Smith, C. \& Sithole, S.L., 2013, Fundamentals of social research methods: An African perspective, 5th edn., Juta \& Company Ltd., Cape Town.

Boddy, C.R., 2016, 'Sample size in qualitative research', Qualitative Market Research 19(4), 426-432. https://doi.org/10.1108/QMR-06-2016-0053

Branine, M., 2008, 'Graduate recruitment and selection in the UK: A study of the recent changes in methods and expectations', Career Development International 13(6), 497-513. https://doi.org/10.1108/1362043081090166

Braun, V. \& Clarke, V., 2019, 'To saturate or not to saturate? Questioning data saturation as a useful concept for thematic analysis and sample-size rationales', Qualitative Research in Sport, Exercise and Health 13(2), 201-216. https://doi. org/10.1080/2159676X.2019.1704846

Breaugh, J.A., 2013, 'Employee recruitment', Annual Review of Psychology 64(1), 389-416. https://doi.org/10.1146/annurev-psych-113011-143757

Cedefop, 2016, European sectoral trends: The next decade (Research paper No. 8093). European Centre for the Development of Vocational Training, Thessaloniki.

Deloitte, 2018, The rise of the social enterprise: 2018, Deloitte Global Human Capital Trends, viewed 15 September 2020, from https://www2.deloitte.com/content/ dam/insights/us/articles/HCTrends2018/2018-HCtrends_Rise-of-the-socialdam/insights/us/

Duarte, J., 2017, 'Skilled young artisans needed', Pretoria News, viewed 12 February 2020, from https://www.iol.co.za/pretoria-news/skilled-young-artisans-needed-10816669.

Dufour, I.F. \& Richard, M., 2019, 'Theorizing from secondary qualitative data: A comparison of two data analysis methods', Cogent Education 6(1), 1690265. https://doi.org/10.1080/2331186X.2019.1690265

DuRose, L. \& Stebleton, M.J., 2016, 'Lost in translation: Preparing students to articulate the meaning of a college degree', Journal of College \& Character 17(4) 271-277. https://doi.org/10.1080/2194587X.2016.1230759

Ekwoaba, J.O., Ikeije, U.U. \& Ufoma, N., 2015, 'The impact of recruitment and selection criteria on organizational performance', Global Journal of Human Resource Management 3(2), 22-33, viewed 20 April 2020, from https://www. eajournals.org/wp-content/uploads/The-Impact-of-Recruitment-and-SelectionCriteria-on-Organizational-Performance.pdf.

Fazio, M., Fernández-Coto, R. \& Ripani, L., 2016, Apprenticeships for the XXI century: A model for Latin America and the Caribbean?, Inter-American Development Bank, viewed 12 February 2020, from https://publications.iadb.org/en/apprenticeshipsxxi-century-model-latin-america-and-caribbean.

Fernández-Aráoz, C., 2014, '21st-century talent spotting', Harvard Business Review, viewed 15 September 2020, from https://hbr.org/2014/06/21st-century-talentspotting.

Forsblom, L., Negrini, L., Gurtner, J-L. \& Schumann, S., 2016, 'Dropouts in Swiss vocational education \& the effect of training companies' trainee selection methods', Journal of Vocational Education \& Training 68(4), 399-415. https://doi. org/10.1080/13636820.2016.1222596

Fox, K.F., 2018, 'Leveraging a leadership development framework for career readiness', New Directions for Student Leadership 157, 13-26. https://doi.org/10.1002/ yd. 20276
Gambin, L. \& Hogarth, T., 2015, 'Factors affecting completion of apprenticeship training in England', Journal of Education and Work 29(4), 470-493. https://doi. training in England', Journal of Education
org/10.1080/13639080.2014.997679

Giffi, C., McNelly, J., Dollar, B., Carrick, G., Drew, M. \& Gangula, B., 2015, 'Overwhelming support: U.S. public opinions on the manufacturing industry', Deloitte, viewed 12 February 2020, from https://www2.deloitte.com/content/dam/Deloitte/us/ Documents/manufacturing/us-mfg-public-perception-manufacturing-021315. PDF.

Government Gazette, 2015, Draft national artisan development trade test pass rate and quality improvement strategy, Vol. 602, No. 39077, viewed 15 September 2020, from https://www.dhet.gov.za/LegislationActs/Draft $\% 20$ National\%20Artisan $\% 20$ Development $\% 20$ Trade $\% 20$ Test $\% 2$ Pass $\% 20$ Rate $\% 20$ and $\% 20$ Quality $\% 20$ Development\%20Trade \%20Test $\% 20$
Improvement $\% 20$ Strategy\%202015.pdf.

Government Gazette, 2018, National list of occupations in high demand: 2018 (Vol. 636, No. 41728), viewed 15 September 2020, from https://www.dhet. gov.za/Information $\% 20$ Systems $\% 20$ Coordination/GAZETTE.pdf.

Gump, S.E., 2006, 'Who gets the job? Recruitment and selection at a 'secondgeneration' Japanese automotive components transplant in the US', International Journal of Human Resource Management 17(5), 842-859. https://doi.org/10.1080 /09585190600640877

Hafni, R.N., Herman, T., Nurlaelah, E. \& Mustikasari, L., 2020, 'The importance of science, technology, engineering, and mathematics (STEM) education to enhance students' critical thinking skill in facing the industry 4.0', Journal of Physics: Conference Series 1521, 042040. https://doi.org/10.1088/1742-6596/1521/4/042040

Hauschildt, U., 2018, A review of methodologies for reviewing the costs and benefits of in-company apprenticeship training, viewed 20 April 2020, from https://www.ilo.org/wcmsp5/groups/public/---ed_emp/documents/ publication/wcms_725494.pdf.

Heutter, J., 2020, TechForce finds technician 'shortage continues to worsen', notes COVID-19 might help supply, viewed 15 November 2020, from https://www. repairerdrivennews.com/2020/09/02/techforce-finds-technician-shortagecontinues-to-worsen-notes-covid-19-might-help-supply/.

Hill, A. \& Dalley-Trim, L., 2008, 'Hanging in there: What makes a difference in the first year of an apprenticeship', Youth Studies Australia 27(1), 36-42, viewed 16 September 2020, from https://0-web.a.ebscohost.com.wam.seals.ac.za/ ehost $/$ pdfviewer/pdfviewer?vid $=5 \&$ sid $=740 \mathrm{dc} 5$ a $2-3487-4 \mathrm{f} 22-8 \mathrm{~d} 5 \mathrm{f}$ a60e4adc9c9b\%40sdc-v-sessmgr05

Hoffman, M., Kahn, L.B. \& Li, D., 2018, 'Discretion in hiring', The Quarterly Journal of Economics 133(2), 765-800. https://doi.org/10.1093/qje/qjx042

Horn, D., 2016, 'The effectiveness of apprenticeship training: A within-track comparison of workplace-based and school-based vocational training in Hungary', Social Science Research 55, 139-154. https://doi.org/10.1016/j.ssresearch.2015.09.002

Imdorf, C., 2017, 'Understanding discrimination in hiring apprentices: How training companies use ethnicity to avoid organisational trouble', Journal of Vocational Education \& Training 69(3), 405-423. https://doi.org/10.1080/13636820.2016.12 Education
78397

Imdorf, C. \& Leemann, R.J., 2012, 'New models of apprenticeship and equal opportunity: Do training networks enhance fair hiring practices?', Journal of Vocational Education \& Training 64(1), 57-74. https://doi.org/10.1080/13636820. 2011.622445

Kilcarr, S., 2016, Is the technician shortage becoming a catastrophe?, viewed 20 February 2020, from https://www.fleetowner.com/fleet-management/article/21692967/isthe-technician-shortage-becoming-a-catastrophe.

Kindsiko, E. \& Poltimäe, H., 2019, 'The poor and embarrassing cousin to the gentrified quantitative academics: What determines the sample size in qualitative interviewbased organization studies?', Forum: Qualitative Social Research 20(3). https:// doi.org/10.17169/fqs-20.3.3200

Korsgaard, S., 2013, 'It's really out there: A review of the critique of the discovery view of opportunities', International Journal of Entrepreneurial Behavior \& Research 19(2), 130-148. https://doi.org/10.1108/13552551311310347

Kramer, M., Tallant, K., Goldberger, A.E. \& Lebus, F., 2015, The global STEM paradox, The New York Academy of Sciences, New York, NY, viewed 14 September 2020, from https://www.fsg.org/publications/global-stemparadox\#download-area.

ManpowerGroup, 2018, Talent shortage survey 2018, viewed 12 February 2020, from https://go.manpowergroup.com/hubfs/TalentShortage $\% 202018 \% 20$ (Global)\%20Assets/PDFs/MG_TalentShortage2018_lo\%206_25_18_FINAL.pdf.

Martin, L.C. \& Smith, R.O., 2011, 'Pre-apprenticeship urban workforce training programs', Adult Learning 22(1), 23-27. https://doi.org/10.1177/104515951102200105

Mateus, A.D., Allen-lle, C. \& Iwu, C.G., 2014, 'Skills shortage in South Africa: Interrogating the repertoire of discussions', Mediterranean Journal of Social Interrogating the repertoire of discussions', Mediterranean Jo
Science 5(6), 63-77. https://doi.org/10.5901/mjss.2014.v5n6p63

merSETA, 2016, Tracer study: Final report 30 March 2016, viewed 20 April 2020, from https://www.Imip.org.za/document/tracer-study-final-report.

Mohrenweiser, J., 2016, 'Recruitment and apprenticeship training', Industrielle Beziehungen 23(1), 6-24. https://doi.org/10.1688/IndB-2016-01-Mohrenweiser

Mottram, R., Clarke, A. \& Downs, S., 1980, 'Recruiting apprentices: The use of the job disposition questionnaire', Journal of Occupational Psychology 53, 265-279. https://doi.org/10.1111/j.2044-8325.1980.tb00033.x

Mummenthey, C. \& Du Preez, R., 2010, 'Implementing efficient and effective learnerships in the construction industry', South African Journal of Industrial Psychology 36(1), 1-11. https://doi.org/10.4102/sajip.v36i1.766

Nomvete, S., Adams, W., \& Moloto, K. (2020). Final sector skills plan update 2021/2022. merSETA. viewed 01 December 2021, from https://www.merseta.org.za/wpcontent/uploads/2021/04/Sector-Skills-Plan-2021-22.pdf 
Naidoo, M. \& Hoque, M., 2017, 'Reducing youth unemployment beyond the youth wage subsidy: A study of Simtech apprentices', South African Journal of Human Resource Management 15, 1-10. https://doi.org/10.4102/sajhrm. v15i0.845

Okoli, C. \& Schabram, K., 2010, 'A guide to conducting systematic literature review of information systems research', Spouts: Working Papers on Information Systems 10, 26. https://doi.org/10.2139/ssrn.1954824

Pandor, G.M.N., 2018, Draft national artisan development strategy and implementation plan 2017, merSETA, viewed 17 September 2020, from https:// www.merseta.org.za/Portals/0/announcements/Draft $\% 20$ National $\% 20$ Artisan $\% 20$ Development $\% 20$ Strategy $\% 20$ And $\% 2$ Implementation $\% 20$ Plan $\% 20$ 2017\%20-\%20For\%20Public\%20Comment.pdf.

Peo, D., 2013, Strengthening leadership in closing the skills gap: An overview of merSETA research-in-action, merSETA, viewed 20 April 2020, from https://www. merseta.org.za/innovation, researchanddevelopment.asp/.

Pret, T. \& Cogan, A., 2019, 'Artisan entrepreneurship: A systematic literature review and research agenda', International Journal of Entrepreneurial Behavior and Research 25(4), 592-614. https://doi.org/10.1108/IJEBR-03-2018-0178

Puchert, J.I., Dodd, N. \& Viljoen, K.L., 2017a, 'Secondary education as a predictor of aptitude: Implications for selection in the automotive sector', South African Journal of Industrial Psychology 43(0), a1416. https://doi.org/10.4102/sajip. v43i0.1416

Puchert, J.I., Dodd, N. \& Viljoen, K.L., 2017b, 'The relationship between type of secondary education and subject choice with technically-oriented aptitudes for automotive operators', South African Journal of Industrial Psychology 43(0), a1435. https://doi.org/10.4102/sajip.v43i0.1435

Qonde, G.F., 2018, Statistics on post-school education and training in South Africa: 2016, Department of Higher Education and Training, viewed 23 June 2020, from https://www.dhet.gov.za/DHET\%20Statistics\%20Publication/Statistics $\% 20$ on $\% 20$ Post-School\%20Education $\% 20$ and $\% 20$ Training $\% 20$ in $\% 2$ South $\% 20$ Africa $\% 20$ 2016.pdf.

Qonde, G.F., 2019, Skills supply and demand in South Africa, Department of Highe Education and Training, viewed 23 June 2020, from https://www.dhet.gov.za/ SiteAssets/Report $\% 20$ on $\% 20$ Skills $\% 20$ Supply $\% 20$ and $\% 20$ Demand $\% 20$ in $\% 20$ South\%20Africa_\%20March\%202019.pdf.

Risler, M. \& Zhiqun, Z., 2013, Apprenticeship and small and medium-sized enterprises: The China case, Regional Association for Vocational Teacher Education in Asia, viewed 20 February 2020, from https://www.tvet-online.asia/series/RaD_vol-8_ Risler_Zhiqun.pdf.

Rousseau, D.M., Manning, J. \& Denyer, D., 2008, Evidence in management and organizational science: Assembling the field's full weight of scientific knowledge through syntheses, Annals of the Academy of Management, volume 2, viewed 15 September 2020, from https://pdfs.semanticscholar.org/521f/715df38a7119ea0 536c906c274be012fc1cc.pdf.

Shankar, V., Cooper, A. \& Koh, H., 2016, Reducing youth unemployment in South Africa, The Rockefeller Foundation, viewed 16 September 2020, from https:// youtheconomicopportunities.org/sites/default/files/uploads/resource/ Reducing\%20Youth\%20Unemployment $\% 20$ in $\% 20$ South $\% 20$ Africa.pdf.

Schmidt, F.L., Oh, I.-S. \& Shaffer, J.A., 2016, The validity and utility of selection methods in personnel psychology: Practical and theoretical implications of 100 years of research findings, Working Paper, viewed 23 June 2020, from https://doi. org/10.13140/RG.2.2.18843.26400.

Schmitt, N., 2014, 'Personality and cognitive ability as predictors of effective performance at work', Annual Review of Organizational Psychology and Organizational Behavior 1, 45-65. https://doi.org/10.1146/annurev-orgpsych031413-091255
Schwab, K., 2019, The world economic forum's global competitiveness report 2019, viewed 16 September 2020, from http://www3.weforum.org/docs/WEF TheGlobalCompetitivenessReport2019.pdf.

Shatouri, R.M., Omar, R. \& Igusa, K., 2012, 'Towards a new era of sustainability in the automotive industry: Strategic human resource management and green technology innovation', World Academy of Science, Engineering and Technology 6(9), 217-222, viewed 23 February 2020, from https://www.scholar.waset. $6(9), 217-222$, viewe
org/1307-6892/10249

Sim, J., Saunders, B., Waterfield, J. \& Kingstone, T., 2018, 'Can sample size in qualitative research be determined a priori?', International Journal of Social Research Methodology 21(5), 619-634. https://doi.org/10.1080/13645579.201 8.1454643

Smith, E., 2007, 'Australian employers' strategies to improve the quality of apprentices', Education \& Training 49(6), 459-473. https://doi.org/10.1108/ 00400910710819118

Smith, E., Comyn, P., Kemmis, R.B. \& Smith, A., 2011, 'Australian employers' adoption of traineeships', Journal of Vocational Education and Training 63(3), 363-375. https://doi.org/10.1080/13636820.2011.559267

Straus, S.G., Miles, J.A. \& Levesque, L.L., 2001, 'The effects of videoconference, telephone and face-to-face media on interviewer and applicant judgements in employment interviews', Journal of Management 27(3), 363-381. https://doi. org/10.1177/014920630102700308

Tranfield, D., Denyer, D. \& Smart, P., 2003, 'Towards a methodology for developing evidence-informed management knowledge by means of systematic review' British Journal of Management 14, 207-222. https://doi.org/10.1111/1467 8551.00375

Trindale, R., 2015, 'Is your background screening keeping up with today's hiring challenges?', Employment Relations Today 42(2), 1-7. https://doi.org/10.1002/ ert.21492

Van Rooyen, L., Du Toit, D.H., Botha, E. \& Rothmann, S., 2010, 'Artisan retention in an organisation in South Africa', South African Journal of Human Resource Management 8(1), 1-8. https://doi.org/10.4102/sajhrm.v8i1.300

Vasileiou, K., Barnett, J., Thorpe, S. \& Young, T., 2018, 'Characterising and justifying sample size sufficiency in interview-based studies: Systematic analysis of sample size sufficiency in interview-based studies: Systematic analysis of
qualitative health research over a 15 -year period', BMC Medical Research Methodology 18, 148. https://doi.org/10.1186/s12874-018-0594-7

Vass, J.R. \& Raidani, P., 2018. Facts and figures on skills in manufacturing: Information brief no. 5, 2018. Department: Trade and Industry. Viewed 01 December 2021, from http://www.thedtic.gov.za/wp-content/uploads/publication-Facts_FiguresManufacturing.pdf

Waite, A.M. \& McDonald, K.S., 2019, 'Exploring challenges and solutions facing STEM careers in the 21st century: A human resource development perspective', Advances in Developing Human Resources21(1),3-15.https://doi.org/10.1177/1523422318814482

Webster, J. \& Watson, R.T., 2002, 'Analyzing the past to prepare for the future: Writing a literature review', Management Information Systems Quarterly 26(2), xiii-xxiii, viewed 14 September 2020, from https://www.jstor.org/stable/4132319

Wilson, J., Arshed, N., Shaw, E. \& Pret, T., 2017, 'Expanding the domain of festival research: A review and research agenda', International Journal of Management Reviews 19(2), 195-213. https://doi.org/10.1111/ijmr.12093

Xue, Y. \& Larson, R.C., 2015, 'STEM crisis or STEM surplus? Yes and yes', Monthly Labor Review, May, viewed 20 February 2020, from https://doi.org/10.21916/mlr.2015.14

Ziegler, M., Dietl, E., Danay, E., Vogel, M. \& Bühner, M., 2011, 'Predicting training success with general mental ability, specific ability tests, and (un)structured interviews: A
meta-analysis with unique samples', International Journal of Selection and Assessment 19(2), 170-182. https://doi.org/10.1111/j.1468-2389.2011.00544.x 